
3 Research Square
Preprints are preliminary reports that have not undergone peer review.
They should not be considered conclusive, used to inform clinical practice, or referenced by the media as validated information.

\title{
Variation of rhizosphere bacterial community diversity in the desert ephemeral plant Ferula sinkiangensis across environmental gradients
}

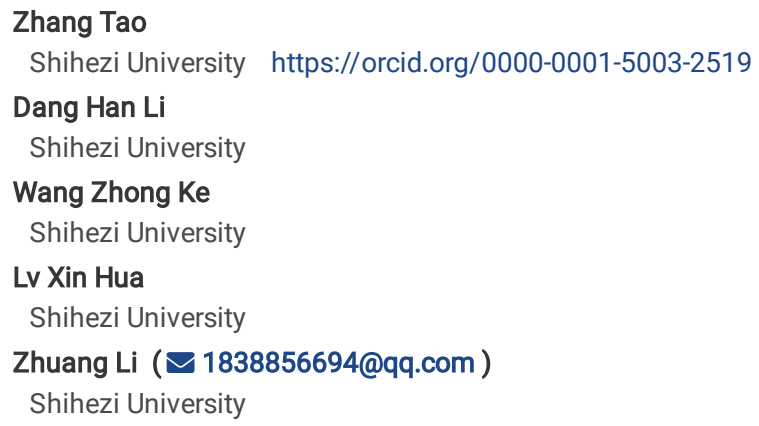




\section{Abstract}

Background Ferula sinkiangensis is a desert short-lived medicinal plant, and its number is rapidly decreasing. Rhizosphere microbial community plays an important role in regulating global biogeochemical cycle, plant growth and adaptability. However, the Ferula sinkiangensis bacterial community and the processes that drive its assembly remain unclear.

Results In this study, based on Illumina HiSeq high-throughput sequencing, we explored the diversity, structure and composition of Ferula sinkiangensis rhizosphere bacterial communities at different slope positions (upper, middle and bottom) and soil depths (0-10 cm, 10-25 cm, 25-40 cm) and their correlation with soil physicochemical properties. Actinobacteria (22.7\%), Proteobacteria (18.6\%), Acidobacteria (14.0\%), Gemmatimonadetes (10.1\%), Cyanobacteria (7.9\%), Bacteroidetes (6.9\%), Planctomycetes (3.9\%), Verrucomicrobia (3.5\%), Firmicutes (3.4\%) and Chloroflexi (3.2\%) were the dominant bacterial phyla in Ferula sinkiangensis rhizosphere soil. Variance analysis showed that the diversity and abundance of rhizosphere bacterial community in Ferula sinkiangensis were significantly different at various slope positions and soil depths. Specifically, the diversity of bacterial community was significantly higher at the top than the bottom of the slope, and the diversity and richness of bacterial community were significantly greater in the $0-10 \mathrm{~cm}$ than the $25-40 \mathrm{~cm}$ soil layer. Linear discriminant effect size (LEfSe) analysis showed the specific phyla and genera of bacteria affected by slope position and soil depth. For example, Planctomycetes, Sphingomonas, Rubrobacter and Adhaeribacter by slope position and significant impact on soil depth. In addition, distance-based redundancy analysis (db-RDA) and variance analysis showed that soil physicochemical factors jointly explained $29.81 \%$ of variation in Ferula sinkiangensis rhizosphere bacterial community structure. There was a significant positive correlation between available phosphorus $₫ A P \llbracket a n d$ the diversity of Ferula sinkiangensis rhizosphere bacterial community $(\mathrm{p}<0.01)$, whereas $\mathrm{pH}$ largely explained the variation of Ferula sinkiangensis rhizosphere bacterial community structure $(5.58 \%, \mathrm{p}<0.01)$, followed by altitude $(5.53 \%)$, total salt $(\mathrm{TS}, 5.21 \%)$ and total phosphorus $(\mathrm{TP}, 4.90 \%)$.

Conclusion Our results revealed the heterogeneity and variation trends of Ferula sinkiangensis rhizosphere bacterial community diversity and abundance on a fine spatial scale (slope position and depth) and shed new light on the interaction mechanisms between Ferula sinkiangensis rhizosphere bacterial community and soil physicochemical properties.

\section{Background}

Ferula sinkiangesis is an umbrella plant, which was included in the pharmacopeia of the People's Republic of China in 1977 [1]. Currently, it is only distributed in the yining region of xinjiang, China, and grows in the grey calcium type arid desert soil. It is a typical desert herb. Ferula sinkiangensis has important medicinal values, such as anti-cancer [2, 3], antioxidant [4], antibacterial [5, 6], anti-inflammatory [7], anti-influenza [5, 8] and anti-diabetes activities [9]. However, the high medicinal value of Ferula sinkiangensis leads to the excessive exploitation by people [10]. As a result, the ecological environment of Ferula sinkiangensis habitat is severely damaged, and the population size decreases sharply. In addition, pests [11] and the low natural reproduction capacity of Ferula sinkiangensis (low seed yield and male sterility) [12] result in weak population recovery, which leads to a shrinkage of the distribution area of Ferula sinkiangensis, from 1400/ha in 1987 to 133 /ha in 2012, and now the species number is still decreasing continuously [13]. Hence, the need to protect Ferula sinkiangensis is imminent.

Soil microbes, as part of the soil biological fertility, play a major role in the function of terrestrial ecosystems. This includes decomposition of organic matter, nutrient cycling (carbon, nitrogen and phosphorus) and pollutant conversion [14-17]. In 1904, Hiltner first proposed the term "rhizosphere region" to describe soil regions affected by root exudates and litter $[18,19]$. Root exudates and litter provide the microorganisms with the carbon and energy needed for survival $[20,21]$. In turn, microorganisms regulate the morphology and physiology of plants [22, 23], promote plant growth and damage repair [24-26], increase plant tolerance to biological and abiotic stresses [27-29], and improve plant ecological adaptability. Thus, the rhizosphere microbiome is considered as the second genome to plant condition [30] and serves on a highly evolved external functional environment for plants [31], which is conducive to plant survival and population recovery. Therefore, our primary purpose in this study was to explore the structure and diversity of bacterial community in the Ferula sinkiangensis rhizosphere.

Mutual interactions exist between microbes, plants and environmental factors. Some scholars influence root exudates by changing water and nutrient availability, and regulate the rhizosphere microbial diversity [26, 32, 33]. The soil pH also has a significant effect on the growth of microbial communities [34, 35]. Nitrogen deposition and precipitation can impact microorganisms [36]. In addition, environmental factors were used to regulate the microbial structure in soil and improve soil fertility in agriculture. Qin et al. adjusted the way of biochar by regulating soil microbes and improving soil environment [37]. Zhou Jing et al. showed that the increase of nitrogen reduced the diversity of fungi communities [38]. However, in most situations, a combination of factors has direct or indirect effects on the rhizosphere. Therefore, understanding the interactions between microbes, plants and the environment in a specific habitat can help to predict the response of organisms to future environmental changes in changing ecosystems.

Giving the spatial heterogeneity of microorganisms [39-41] and the influence of numerous soil physicochemical factors on microorganisms, we hypothesized that(1)the bacterial community structure and diversity of Ferula sinkiangensis rhizosphere are significantly different at various slope positions and soil depths and $\mathbb{2} 2$ there are only a few Soil physicochemical properties having dominant influence on the diversity and structure of the bacterial community in the Ferula sinkiangensis rhizosphere soil.

\section{Materials And Methods}

\subsection{Site description and sampling}

Since it is an ephemeral species, we chose to conduct a pilot study during the Ferula sinkiangesis growing season (April-May). We set the place of Byshidun, Yining, Xinjiang, China as the research plot (earth quality: desert gray calcareous soil, slope: $43^{\circ}$, longitude: 82.083359 , latitude: 43.723121 , Altitude: $993-$ 
$1136 \mathrm{~m}$ ). We designed a $10 \mathrm{~m} \times 5 \mathrm{~m}$ rectangular plot at the top of the slope, in the middle of the slope and at the bottom of the slope of a Ferula sinkiangesis living area. Riley and Barber shaking methods $[42,43]$ were used to collect rhizosphere and non-rhizosphere soil samples in $10 \mathrm{~m} \times 5 \mathrm{~m}$ plots circled at the top, slope and bottom of the slope. Taking the slope top as an example, 3 Ferula sinkiangesis with good growth were randomly selected in the sample plot of $10 \mathrm{~m}$ $\times 5 \mathrm{~m}$, and the whole root systems of 3 Ferula sinkiangesis were collected. Soil samples were collected at 0-10cm, $10 \mathrm{~cm}-25 \mathrm{~cm}$ and $25 \mathrm{~cm}-40 \mathrm{~cm}$ according to the shaking methods $[42,43]$. Collected soil was immediately placed in a $5 \mathrm{ml}$ test tube with sterile tweezers, and then marked on a tube and placed in a liquid nitrogen tank for storage. A total of 18 soil samples were collected at the top of the slope. Specifically, two root zone types (rhizosphere and non-rhizosphere) $\times 3$ depths $(0-10 \mathrm{~cm}, 10 \mathrm{~cm}-25 \mathrm{~cm}$ and $25 \mathrm{~cm}-40 \mathrm{~cm}) \times 3$ replicates (each Ferula sinkiangesis as a repeat). We explored three different plots of top, slope, and bottom, with a total of 54 soil samples $(3 \times 18)$. In addition, we used a mixed labeling system to label the samples. The first group of letters was used to represent the position of the slope, rhizosphere and non-rhizosphere $(E, R$ and $S$ represent the rhizosphere region of the top, middle and bottom of the slope respectively), (NE, NR and NS represent the non-rhizosphere region of the top, middle and bottom of the slope respectively). The second number indicates the depth $(1,2$, and 3 represent $0-10 \mathrm{~cm}, 10-25 \mathrm{~cm}$, and $25-40 \mathrm{~cm}$ depth, respectively) and the third number indicates the number of repetitions. For example, S2.1 represents the first replicate soil sample with a root depth of $10-25 \mathrm{~cm}$ in the roots of Ferula sinkiangesis at the bottom of the slope (Supplementary Table S1).

\subsection{Soil analysis}

Obtained soil samples were naturally air-dried, sieved to $2 \mathrm{~mm}$, and plant impurities were removed for determining physical and chemical properties. Organics contents were determined by external heating with potassium bichromate [44]. Nitrogen content was determined by the perchlorate-sulfuric acid digestion method, and the use of a fox 1035 automatic nitrogen determination apparatus [44]. Total phosphorus contents were assayed by the molybdenum method with an agilent CARY60 UV spectrophotometer $r$ [44]. Total potassium was measured using the acid dissolution - atomic absorption method and a Thermo Scientific Series Atomic Absorption Spectrometer. pH measurements were performed with a mettler tolido FiveEasy Plus pH-meter. Available phosphorus was determined by molybdenum inverse colorimetry after extraction with sodium bicarbonate. Nitrate and ammonium nitrogen was determined by the $0.01 \mathrm{M}$ calcium chloride extraction method using a BRAN + LUEBBE flow analyzer (Supplementary Table S2).

\subsection{DNA extraction, amplification and library generation}

DNA was isolated from each sample using a Centrifugal Soil Genomic DNA Extraction Kit, and the purity and concentration of the DNA were measured by $1 \%$ agarose gel electrophoresis. An appropriate amount of DNA sample was placed in a sterile centrifuge tube and diluted to $1 \mathrm{ng} / \mu \mathrm{L}$ with sterile water. Partial 16S rDNA-based high-throughput sequencing was used to determine the bacterial diversity and community composition according to Caporaso et al [45, 46]. Using diluted DNA as a template, PCR amplification of the V4 region of 16S rRNA gene was performed using barcode-specific primers 806R (5' -

GGACTACHVGGGTWTCTAAT-3') and 515F (5'-GTGCCAGCMGCCGCGGTAA-3'). The V4 region was used because 806R and 515F primers produced the greatest diversity at the bacterial level [47]. Phusion ${ }^{\circledR}$ high-fidelity PCR Master Mix with GC buffer from New England Biolabs was used to ensure the efficiency and accuracy of amplification. PCR products were detected by electrophoresis with $2 \%$ agarose gel, and target bands between $200-300$ bp were cut for further experiments. PCR products were mixed at equal density ratios. The PCR products were purified using Qiagen Gel Extraction Kits (Qiagen, Germany). The recovered purified products were placed in a $1.5 \mathrm{~mL}$ sterile centrifugal tube in a dry ice box and sent to Beijing Compass Biotechnology Co., Ltd for highthroughput sequencing. The library was constructed using a TruSeq ${ }^{\circledR}$ DNA PCR-Free Sample Preparation Kit. The constructed library was quantified by Qubit and qt-PCR. After the library was qualified, it was sequenced using HiSeq2500 PE250.

\subsection{Sequence analysis}

After barcode sequences and primer sequences were cut off, the reads of each sample were spliced with a fast and accurate analysis tool FLASH [48] to obtain the raw tags. Raw tags were carefully filtered [49] to get clean tags of high quality using Qiime (V1.9.1) [50]. Tags quality control process comprised the following operations: a) Tags intercept: raw tags with low quality value (default quality threshold was $\leq 19$ ) of the set length (default length value was 3 ) were truncated; b) Tags length filtering: the tagged data set obtained after interception of tags was further filtered out of the continuous high quality tags whose base length was less than $75 \%$ of the tags length. The tag sequences obtained after the above treatment are compared with the Gold database by UCHIME Algorithm [51] to detect chimeric sequences that were removed [52], to obtain the final effective tags.

Uparse software (Uparse v7.0.1001) [53] was used to cluster the effective tags of all samples, with $97 \%$ sequence identity. Grouping sequences into Operational Taxonomic Units (OTUs). The sequences with the highest occurrence frequency in OTUs were selected as representative of OTUs by using the Mothur method. SILVA [54] SSUrRNA database [55] was used for OTUs annotation to represent species sequence analysis (setting threshold of 0.8-1) and acquire information on taxonomy. The MUSCLE (Version 3.8.31) software [56] was used for fast multi-sequence alignment to obtain the system relationship of all OTUs representative sequences. Finally, the sample with the smallest amount of data was homogenized. Subsequent alpha diversity (a-diversity)and beta diversity $\square \beta$-diversity $\square$ analyses were both based on the homogenized data.

\subsection{Data analysis}

QIIME software (Version 1.9.1) was used to calculate the Observed-species, Chao1, Shannon, and Goods-coverage indices. Chao1, Shannon and Goodscoverage indices can be used to evaluate the richness, diversity and sequencing depth of samples respectively [57]. In addition, R software (Version 2.15.3) was used to draw the dilution curve (Supplementary Figure S1) to reflect the rationality of sequencing data volume. $\beta$-diversity analysis was performed on weighted and unweighted unifac with the QIIME software (version 1.7.0). The latter software was used as a hierarchical clustering method to interpret the distance matrix using average link, and arithmetic mean (UPGMA) clustering was used for the unweighted pair method. The linear discriminant analysis (LDA) effect size (LEfSe) was used to identify statistically significant differences between groups.

One-way ANOVA (Tukey test) was used to assess differences in bacterial relative abundance or diversity between samples. Pearson correlation analysis was performed to assess the interrelationship between soil properties and the dominant bacterial species. In addition, distance-based redundancy analysis (db- 
RDA) and variance partitions were performed to study the relationship between the composition of the rhizosphere, soil properties and non-soil parameters. This was carried out with the Canoco statistical software (version 5.0) and default parameters (vegan package).

\section{Results}

\subsection{Structure and composition of Ferula sinkiangensis rhizosphere soil bacterial community.}

All samples contained 4,634,264 raw tags in total, filtering out the low quality tags and removing the chimeric sequences to obtain the final 4,405,120 effective sequences. On average, these reads were grouped into 4,017 bacterial OTUs and contained a total of 75,570 taxon tags per sample (Supplementary Table S3).

Species sequence analysis identified 60 phyla and 901 genera of bacteria. The most abundant phyla were (Figure 1): Actinobacteria (22.7\%), Proteobacteria (18.6\%), Acidobacteria (14.0\%), Gemmatimonadetes (10.1\%), Cyanobacteria (7.9\%), Bacteroidetes (6.9\%), Planctomycetes (3.9\%), Verrucomicrobia (3.5\%), Firmicutes (3.4\%), and Chloroflexi (3.2\%). The most abundant genera were (Supplementary Figure S2): RB41 (3.03\%), Sphingomonas (1.64\%), Rubrobacter (1.43\%), Gaiella (1.10\%), Pseudarthrobacter(1.01\%), Solirubrobacter (0.85\%), Gemmatimonas (0.71\%), Bacteroides $(0.63 \%)$, Acinetobacter $(0.57 \%)$, Adhaeribacter (0.57\%), Haliangium (0.47\%), Staphylococcus (0.43\%), Rhodococcus $(0.42 \%)$, Pseudomonas (0.40\%), Bacillus ( $0.38 \%)$; the remaining $76.59 \%$ include genera outside the top 30 of the annotated list and the parts not annotated. Moreover, multivariate analysis of variance revealed significant differences between Shannon and Chao1 indexes at the top and bottom of the slope. The diversity and richness of the bacterial community were affected by the slope position, as illustrated by a higher bacterial diversity and richness at the top of the slope compared to the bottom. In addition, there were significant differences in Shannon and Chao1 indices at different soil depths and different rhizosphere regions (rhizosphere and non-rhizosphere). The diversity and richness of bacterial communities are thus affected by soil depth and rhizosphere regions. The diversity and richness of bacterial communities at soil depths of 0-10 cm were significantly higher than that in $10-25 \mathrm{~cm}$ and $25-40 \mathrm{~cm}$. Furthermore, the diversity and richness of bacteria were significantly higher in the rhizosphere than in the non-rhizosphere (Supplementary Table S4).

\subsection{Relationships between root zone (rhizosphere and non-rhizosphere), slope position, soil depth and dominant bacteria (phyla and genera).}

Multivariate analysis of variance and LDA effect size analysis showed that Cyanobacteria, Actinobacteria, Acidobacteria, Chloroflexi and Firmicutes were significantly changed in the rhizosphere and non-rhizosphere. The specific abundance of Actinobacteria, Chloroflexi and Acidobacteri in the rhizosphere was significantly higher than that observed in the non-rhizosphere. However, the relative abundance of Cyanobacteria and Firmicutes in the non-rhizosphere was significantly higher than that observed in the rhizosphere. Moreover, Firmicutes, Planctomycetes and Verrucomicrobia were significantly affected by the slope position, as shown by a significantly higher relative abundance of Firmicutes at the bottom of the slope compared to the top of the slope. The opposite was observed for Verrucomicrobia. In addition, the relative abundance of Planctomycetes in the middle and top of the slope was significantly higher than at the bottom of the slope. Soil depth had a significant effect on the relative abundance of Cyanobacteria, Bacteroidetes, Acidobacteria and Planctomycetes. The relative abundance of Planctomycetes and Acidobacteria at a $0-10 \mathrm{~cm}$ soil depth was significantly higher than at $25-40 \mathrm{~cm}$, and Bacteroidetes were more abundant at $0-10 \mathrm{~cm}$ than at a $10-25 \mathrm{~cm}$ soil depth. However, the relative abundance of Cyanobacteria at $10-40 \mathrm{~cm}$ soil depth was significantly higher than that observed at $0-10 \mathrm{~cm}$ soil depth (Figure 2 and Supplementary Table S5). Figure 2 also shows specific differences in the distribution of different bacterial genera.

\subsection{Relationship between slope position, soil depth and Ferula sinkiangensis rhizosphere soil physicochemical properties.}

Spearman correlation analysis showed that most variables including total phosphorus content (TP), ammonium nitrogen content (AN), nitrate nitrogen content (NN) and available phosphorus content (AP) are associated with altitude (Table 1). Specifically, altitude was negatively correlated with AN and NN. On the other hand, a significant positive correlation was observed between altitude and TP or AP. Total organic carbon content (TOC), total nitrogen content (TN), and total potassium content (TK) were positively correlated with AP. TOC was positively correlated with TN, total salt content (TS) and AP. TS was negatively correlated with $\mathrm{pH}$, and TP was positively correlated with altitude. However, TP was negatively correlated with AN (Table 1). In addition, multivariate analysis of variance showed that slope position was significantly correlated with most soil physicochemical properties including TOC, TP, TK, NN, AN, AP, and TS. However, only a few soil physicochemical properties, including AP, TS and pH, had a significant correlation with depth. Specifically, TOC, TP, TK, AP, and TS were significantly higher at the top than the middle of slope. The contents of TP and AP at the top of slope were significantly higher than those at the bottom and middle of slope. Interestingly, the content of AN was significantly higher at the bottom than at the top and middle of slope. In terms of depth, the content of AP and $\mathrm{pH}$ in 0-10 cm soil were significantly higher than those in 25-40 cm soil (Supplementary Table S6).

\section{4 pH largely explained the variation of Ferula sinkiangesis rhizosphere bacterial community structure}

Across all samples, soil AP showed a significant positive correlation with a-diversity of the bacterial community $(r=0.538, p<0.01)$. Soil TP and TK and the adiversity displayed a significant positive correlation (Shannon index, $r=0.495$ and 0.405 , respectively, $p<0.05$, Table 2). In addition, distance-based redundancy analysis (db-RDA) also showed a correlation between soil physicochemical properties and the distribution of bacterial communities in the rhizosphere of Ferula sinkiangesis (Figure 3). All the soil physicochemical factors explained $29.81 \%$ of the variation in the rhizosphere bacterial community structure of Ferula sinkiangensis. The pH explained 5.58\% of variation, altitude explained $5.53 \%$, TS 5.21\%, TP $4.90 \%$, NN 3.89\% and AP explained 3.60\%. Among them, $\mathrm{pH}$, altitude, TS and TP explained the largest proportion of the variation of the bacterial community structure in the rhizosphere of Ferula sinkiangensis (Supplementary Table S7).

\subsection{Spearman correlation analysis between relative abundance of dominant bacteria (phyla and genera) and soil physicochemical properties.}

Although the relative abundance of bacterial phylum has a significant correlation with slope position, soil depth and root zone, the relative abundance of bacterial also has a significant correlation with soil Physicochemical Properties. Table 3 shows the relationship between the top ten dominant bacteria phyla and soil Physicochemical Properties. Specifically, TN, AP and TS have a significant positive correlation with the relative abundance of Actinobacteria; AP and 
TS showed significant positive relationships with Chloroflexi; $\mathrm{pH}$ showed significant positive relationships with Bacteroidetes; Altitude have significant positive relationships with Gemmatimonadetes; AN have significant positive relationships with Verrucomicrobia. Conversely, NN and TS significantly negative correlated with the relative abundances of Gemmatimonadetes; TN and AP showed significant negative relationships with Cyanobacteria. Interestingly, Firmicutes, Proteobacteria, Planctomycetes and Acidobacteria were not significantly related to each variable (Table 3). Moreover, the relationship between the relative abundance of the first thirty-five bacterial phyla and the Physicochemical Properties of the soil is shown in Supplementary Figure 3. In addition, correlation analysis between relative abundance of bacteria genera and soil physicochemical properties showed that $\mathrm{pH}$ and altitude were significantly correlated with most bacteria genera. For example, pH has significant positive correlation with the relative abundance of Adhaeribacter, Altererythrobacter, Gemmatimonas, Hymenobacter, Massilia, Opitutus, Rubellimicrobium and Sphingomonas (Figure 4A). Altitude has significant negative correlation with Blastococcus, Opitutus, RB41, and Rubellimicrobium (Figure 4B).

\section{Discussion}

4.1

The slope position and soil depth changed the diversity and richness of the bacterial community in the rhizosphere of Ferula sinkiangensis

One noteworthy result of our study was that the diversity and richness of the bacterial community in the rhizosphere of Ferula sinkiangensis were significantly different at different slope positions and soil depths (Supplementary Table S4). This result supported our first hypothesis on the bacterial diversity and abundance of Ferula sinkiangensis being sensitive to slope and soil depth variation; importantly, the spatial heterogeneity of bacterial communities was detectable on a small scale; these findings were consistent with the results of Qiqi Sun et al. [58] in exploring the microbial diversity of steep slope soils in the semi-arid Loess Plateau and also Martina et al. [59] who explored the small-scale spatial diversity of temperate forests.

The variation in diversity and richness of bacterial communities along the slope might be attributed mainly to two aspects. 1. Redistribution of nutrients down the slope during rainfall erosion $[60,61]$, causing differences in soil properties (Supplementary Table S6), indirectly affecting the diversity and structure of bacterial communities. 2. The illumination time and intensity differ at various slope positions [62]. For example, there was a longer illumination time at the top of the slope than at the bottom, which was conducive to increased photosynthetic formation of organic compounds by plants, thus increasing the input of organic matter into soil and affecting the bacterial community.

Stratification differences in the diversity and richness of bacterial communities with soil depth were similar to those in the studies of Lopez-Mondejar et al. and Eilers et al. $[63,64]$ mainly due to spatial heterogeneity of nutrients. The topsoil has greater contents of nutrients than the deeper soil layers, with a consequent increase in microbial a-diversity [65]. Secondly, the topsoil microorganisms have higher activity than the deep soil microorganisms. Microbial decomposition and metabolic processes result in a large number of metabolites (including extracellular enzymes), contributing to topsoil nutrient accumulation and thus growth of bacteria.

4.2

Soil pH is a dominant predictor of bacterial community structure but not of community diversity in rhizosphere of Ferula sinkiangensis

Soil pH is considered as the best predictor of bacterial community structure and diversity at different spatial scales and soil types [66-68], and this was consistent with the results we found in this study regarding the composition and variation of the rhizosphere bacterial community in the rhizosphere of Ferula sinkiangensis (Fig. 3 and Supplementary S7). However, the mechanism behind this model is little known, and we propose three relevant hypotheses. 1. Bacteria have a certain range of tolerance to $\mathrm{pH}$, beyond which they cannot survive. The intracellular $\mathrm{pH}$ of many microorganisms is close to neutral [69]. Therefore, any degree of $\mathrm{pH}$ change exerts pressure on some bacterial groups with narrow $\mathrm{pH}$ tolerance and inadaptability, interfering with their growth, affecting their competitiveness [70], and eventually leading to changes in the composition of bacterial communities. 2 . The $\mathrm{pH}$ may not directly affect the structure of bacterial communities, but it may affect the physicochemical properties of soils directly and indirectly. For example, there was a significant negative correlation between $\mathrm{pH}$ and salt content (Table 1); in addition, $\mathrm{pH}$ affects the availability of nutrients and heavy metal ions in soil [71, 72]. Therefore, $\mathrm{pH}$ can be used as an integrated variable to combine with other factors in influencing the community structure of bacteria. 3 . Dakora et al. showed that some plants actively affect soil bacterial communities by changing soil pH through root exudates [22]. In addition, studies have shown that plant growth was passively influenced by $\mathrm{pH}$, regulating the amount and composition of root secretions [72, 73], which further influences nutrient availability, enzyme activity and microbial abundance $[74,75]$. Of course, $\mathrm{pH}$, whether actively or passively, plays an important role in influencing the structure of bacterial communities.

Interestingly, we found in this study there was a significant correlation between AP (but not $\mathrm{pH}$ ) and Ferula sinkiangensis rhizosphere bacterial diversity. This suggested that $\mathrm{pH}$ was not always a universal predictor of bacterial community diversity. Depending on habitat environment and soil type, there might be factors that explain bacterial diversity better than $\mathrm{pH}$. The reason why AP has a significant relationship with bacterial community diversity was a relationship between $\mathrm{C}$ mineralization and $\mathrm{P}$ availability. Previous studies showed that in the absence of $\mathrm{P}$, the retention time of litter was longer and the mineralization of unstable $C$ was inhibited. This even had a negative effect on the carbon sequestration in cultivated lands [76, 77]. However, $C$ is the main source of energy for microorganisms and interferes with their growth [78]. The response of $\mathrm{C}$ mineralization to $\mathrm{P}$ availability directly impacts the biodiversity.

4.3

The factors affecting the rhizosphere bacterial community of Ferula sinkiangensis applied in conservation and commercial cultivation of Ferula sinkiangensis

Microorganisms can be closely involved in soil nutrient cycle, improved soil nutrient status and optimized soil structure [79-81]. Provide suitable soil environment for plant growth. Considering the important role of microorganisms in plant growth and development, Enkatachalam et al. put forward the "Belowground Solutions to an Aboveground Problem" viewpoint [31]. Meanwhile, the research of some scholars also confirmed this viewpoint. For example, Hoflich et al. stimulated plant growth by inoculation with symbiotic and associative rhizosphere microorganisms [82], and the microorganisms discovered by

Page 5/11 
Horace et al. regulated plant growth by producing various secondary metabolites [83]. In addition, some scholars applied phosphate, potash and nitrogen fertilizers and organic matter to alter the microbial community diversity and influence plant growth [84, 85]. Therefore, we hope that the discovery of pH, AP, TP and TK significantly influencing the bacterial community diversity and structure in the rhizosphere of Ferula sinkiangensis (Table 2 and Supplementary Table S7) can be applied in conservation and commercial cultivation of Ferula sinkiangensis.

\section{Conclusion}

Although Ferula sinkiangensis population continues to decline, the research conducted on Ferula sinkiangensis is still focused mainly on medicinal properties; in contrast, the research on habitat ecology, plant physiology and soil is rare, restricting the capacity to conserve Ferula sinkiangensis. In this study, we explored the diversity and structural composition of the rhizosphere bacterial community in the rhizosphere of Ferula sinkiangensis. However, bacterial communities are made up of a wide variety of bacteria, some of which are beneficial to plant growth and development, some of which are neutral, and some of which are not conducive to plant growth and development [86]. This requires us to conduct further characterization in subsequent studies, to identify the bacterial populations conducive to the growth and development of Ferula sinkiangensis. The spatial heterogeneity of microorganisms has been shown [3941], but there are few studies on sloping land and soil depth. Our study revealed trends in bacterial community diversity at different slopes and soil depths, which will contribute to our understanding of the microbially-mediated carbon cycle in soil. Our study demonstrated the universality of pH prediction of bacterial community structure, but also showed that $\mathrm{pH}$ effects on bacterial community diversity might be limited under the influence of specific habitats and soil types. In addition, the dominant effects of $\mathrm{pH}, \mathrm{AP}$, TK and TP on the bacterial community were identified, and we considered using them in the conservation and commercial culture of Ferula sinkiangensis. By adjusting $\mathrm{pH}$ value and applying phosphate and potassium fertilizers, the diversity and structure of bacterial community might be affected, and soil structure might be improved to provide suitable soil environment for the growth of Ferula sinkiangensis. Exploring the optimal amount and proportion of fertilizers needs to be done in the future studies.

\section{Abbreviations}

\section{LEfSe}

Linear discriminant effect size

$\mathrm{db}-\mathrm{RDA}$

distance-based redundancy

TS

Total salt content

AP

Available phosphorus content

AN

Ammonium nitrogen content

NN

Nitrate nitrogen content

TP

Total phosphorus content

TN

Total nitrogen content

TK

Total potassium content

TOC

Total organic carbon content

\section{Declarations}

\section{Ethics approval and consent to participate}

Ethical issues are not applicable in this study, and the collection of samples in the experiment was approved by the local government (government of yining county, xinjiang, China).

\section{Consent for publication}

Not Applicable

\section{Availability of data and material}

All data generated or analysed during this study are included in this published article [and its supplementary information files].

\section{Competing interests}

We declare that the research was conducted in the absence of any commercial or financial relationships.

\section{Funding}


This study was supported by the Chinese National Basic Research Program (2014CB954203) and the National Natural Science Foundation of China $(31360139,41561010$ and 31560177$)$. All funding agencies provided financial support only and did not participate in the design of experiments, sampling and manuscript writing tasks.

Authors' contributions

Tao Zhang is the first author of this article, Li Zhuang are the corresponding authors, $\mathrm{T} Z$ and L Z designed this study and conducted data analysis, TZ, Hanli Dang , ZhongKe Wang and XinHhua Lv conducted the research, TZ wrote the manuscript and had primary responsibility for the final content. All authors read and approved the final manuscript

Acknowledgements

In this study, we would like to thank professor LZ for his guidance, all the authors for their joint efforts, and Ferula sinkiangensis research enthusiasts who provided guidance services in this experiment.

\section{References}

1. Qian ZZ, Dan Y, Liu YZ, Peng Y: PharmacopoeiaofthePeople'sRepublicofChina(2010Edition):AMilestoneinDevelopmentofChina'sHealthcare. Chinese Herbal Medicines 2010, 02(2):157-160.

2. Suzuki K, Okasaka M, Kashiwada Y, Takaishi Y, Honda G, Ito M, Takeda Y, Kodzhimatov OK, Ashurmetov O, Sekiya M: Sesquiterpene lactones from the roots of Ferula varia and their cytotoxic activity. Journal of Natural Products 2007, 70(12):1915-1918.

3. Mansour Z, Ben Jannet H, Sylvie C, Jalloul B: Chemical composition, biological and cytotoxic activities of plant extracts and compounds isolated from Ferula lutea. Molecules 2014, 19(3):2733-2747.

4. Kartal N, Sokmen M, Tepe B, Daferera D, Polissiou M, Sokmen A: Investigation of the antioxidant properties of Ferula orientalis L. using a suitable extraction procedure. Food Chemistry 2007, 99(2):584-589.

5. El-Razek MHA, Ohta S, Hirata T: Terpenoid Coumarins of the Genus Ferula. Cheminform 2003, 34(22).

6. Matejić JS, Džamić AM, Mihajilov-Krstev T, Ranđelović VN, Krivošej ZĐ, Marin PD: Total phenolic content, flavonoid concentration, antioxidant and antimicrobial activity of methanol extracts from three Seseli L. taxa. Central European Journal of Biology 2012, 7(6):1116-1122.

7. Motai T, Kitanaka S: Sesquiterpene chromones from Ferula fukanensis and their nitric oxide production inhibitory effects. Journal of Natural Products 2004, 67(3):432-436.

8. Lee CL, Chiang LC, Cheng LH, Liaw CC, Abd El-Razek MH, Chang FR, Wu YC: Influenza A (H(1)N(1)) Antiviral and Cytotoxic Agents from Ferula assafoetida. Journal of Natural Products 2009, 72(9):1568-1572.

9. Bagheri SM, Mohammadsadeghi H, Dashtir MH, Mousavian SMM, Aghaei ZA: Effect of Ferula assa-foetida oleo-gum-resin on renal function in normal Wistar rats. Indian J Nephrol 2016, 26(6):419-422.

10. Xu E, Zhang H: Spatially-explicit sensitivity analysis for land suitability evaluation. Applied Geography 2013, 45(45):1-9.

11. Zhu J, Li XJ, Jia XG: A preliminary study on the ecological habit of the pest of Ferula sinkiangensis-longicorn longicornis with white hair. In: Proceedings of the 9th national symposium on natural drug resources: 2010.

12. Tan GY, He S, Yao F: Male sterility and morphological observation of Ferula sinkiangensis. In: 70th anniversary annual meeting of Chinese botanical society: 2003.

13. Xie C, Shi M, Guo B, Shi L, Zeng F, Fu D, Li X, Jia X: Resource Investigation for Endangered Wild Ferula sinkiangensis Based on Low Altitude Remote Sensing. 2014.

14. Rodríguez H, Fraga R: Phosphate solubilizing bacteria and their role in plant growth promotion. Biotechnology Advances 1999, 17(4-5):319-339.

15. Bardgett RD, Freeman C, Ostle NJ: Microbial contributions to climate change through carbon cycle feedbacks. The ISME Journa/ 2008.

16. Schimel DS: Terrestrial ecosystems and the carbon cycle. Global Change Biology 2010, 1(1):77-91.

17. Thielebruhn S: Linking soil biodiversity and agricultural management. Current Opinion in Environmental Sustainability 2012, 4(5):523-528.

18. Bais HP, Weir TL, Perry LG, Gilroy S, Vivanco JM: THE ROLE OF ROOT EXUDATES IN RHIZOSPHERE INTERACTIONS WITH PLANTS AND OTHER ORGANISMS. Annual Review of Plant Biology 2006, 57(1):233-266.

19. Hiltner, L: Über neuere Erfahrungen und probleme auf dem gebiete der Bodenbakteriologie unter besonderer Berücksichtigung der gründüngung und Brache. Arbeit. Deut. Landw. Ges. Berlin 1904,98:59-78.

20. De Deyn GB, Cornelissen JH, Bardgett RD: Plant functional traits and soil carbon sequestration in contrasting biomes. Ecology Letters 2008, 11(5):516531.

21. Bulgarelli D, Garrido-Oter R, Münch PC, Weiman A, Dröge J, Pan Y, Mchardy AC, Schulze-Lefert P: Structure and function of the bacterial root microbiota in wild and domesticated barley. Cell Host \& Microbe 2015, 17(3):392-403.

22. Dakora FD, Phillips DA: Root exudates as mediators of mineral acquisition in low-nutrient environments. Plant \& Soil 2002, 245(1):201-213.

23. Matiru VN, Dakora FD: Xylem transport and shoot accumulation of lumichrome, a newly recognized rhizobial signal, alters root respiration, stomatal conductance, leaf transpiration and photosynthetic rates in legumes and cereals. New Phytologist 2010, 165(3):847-855.

24. Gull M, Hafeez FY, Saleem M, Malik KA: Phosphorus uptake and growth promotion of chickpea by co-inoculation of mineral phosphate solubilising bacteria and a mixed rhizobial culture. Australian Journal of Experimental Agriculture 2004, 44(6):142-153.

Page $7 / 11$ 
25. Rodriguez RJ, Henson J, Van VE, Hoy M, Wright L, Beckwith F, Kim YO, Redman RS: Stress tolerance in plants via habitat-adapted symbiosis. Isme Journal 2008, 2(4):404.

26. Liu L, Liu S, Chen F, Yang X, Yang C, Bingqi WU, Zhang M, Zhao J: Effect of endophytic bacteria inoculation on cadmium uptake in Solanum nigrum L. Acta Scientiae Circumstantiae 2013, 33(12):3368-3375.

27. Mayak S, Tirosh T, Glick BR: Plant growth-promoting bacteria confer resistance in tomato plants to salt stress. Plant Physiology \& Biochemistry 2004, 42(6):565-572.

28. Shimon, TIROSH, Tsipora, GLICK, Bernard R: Plant growth-promoting bacteria that confer resistance to water stress in tomatoes and peppers. Plant Science 2004, 166(2):525-530.

29. Rolli E, Marasco R, Vigani G, Ettoumi B, Mapelli F, Deangelis ML, Gandolfi C, Casati E, Previtali F, Gerbino R: Improved plant resistance to drought is promoted by the root-associated microbiome as a water stress-dependent trait. Environmental Microbiology 2014, 17(2):316-331.

30. Berendsen RL, Pieterse CMJ, Bakker PAHM: The mizosphere microbiome and plant health. Trends in Plant Science 2012, 17(8):478-486.

31. Lakshmanan V, Selvaraj G, Bais HP: Functional Soil Microbiome: Belowground Solutions to an Aboveground Problem. Plant Physiology 2014, 166(2):689700.

32. Howard AG, Comber SDW, Kifle D, Antai EE, Purdie DA: Arsenic Speciation and Seasonal Changes in Nutrient Availability and Micro-plankton Abundance in Southampton Water, U.K. Estuarine Coastal \& Shelf Science 1995, 40(4):435-450.

33. Nessner KV, Taketani RG, Lançoni MD, Andreote FD, Mendes R, Soares dMI: Water regime influences bulk soil and Rhizosphere of Cereus jamacaru bacterial communities in the Brazilian Caatinga biome. Plos One 2013, 8(9):e73606.

34. Schnittler M, Stephenson SL: Myxomycete biodiversity in four different forest types in Costa Rica. Mycologia 2000, 92(4):626-637.

35. Nascimento AL, Souza AJD, Andrade PAMD, Diniandreote F, Gomes ARC, Oliveira FC, Regitano JB: Sewage Sludge Microbial Structures and Relations to Their Sources, Treatments, and Chemical Attributes. Frontiers in Microbiology 2018, 9(1462):1462-.

36. Treseder KK: Nitrogen additions and microbial biomass: a meta-analysis of ecosystem studies. Ecology Letters 2010, 11(10):1111-1120.

37. Yao Q, Liu J, Yu Z, Li Y, Jin J, Liu X, Wang G: Three years of biochar amendment alters soil physiochemical properties and fungal community composition in a black soil of northeast China. Soil Biology \& Biochemistry 2017, 110:56-67.

38. Jing Z, Xin J, Zhou B, Zhao B, Ma M, Guan D, Li J, Chen S, Cao F, Shen D: Thirty four years of nitrogen fertilization decreases fungal diversity and alters fungal community composition in black soil in northeast China. Soil Biology \& Biochemistry 2016, 95:135-143.

39. Franklin RB, Mills AL: Multi-scale variation in spatial heterogeneity for microbial community structure in an eastem Virginia agricultural field. Fems Microbiology Ecology 2010, 44(3):335-346.

40. Porter SS, Rice KJ: Trade-offs, spatial heterogeneity, and the maintenance of microbial diversity. Evolution;international journal of organic evolution 2013 , 67(2):599-608.

41. Choi JH, Kim GB, Cha CJ: Spatial heterogeneity and stability of bacterial community in the gastrointestinal tracts of broiler chickens. Poultry Science 2014, 93(8):1942-1950.

42. Riley D, Barber SA: Bicarbonate Accumulation and pH Changes at the Soybean (Glycine max (L.) Merr.) Root-Soil Interface1. Soil Science Society of America Journal 1969, 33(6):905-908

43. Riley D, Barber SA: Salt accumulation at the soybean (Glycine max (L.) Merr) root-soil interface. Soil Science Society of America Journal 1970, 34(1):154155.

44. Chen Z, Wu W, Shao X, Li L, Guo Y, Ding G: Shifts in Abundance and Diversity of Soil Ammonia-Oxidizing Bacteria and Archaea Associated with Land Restoration in a Semi-Arid Ecosystem. Plos One 2015, 10(7):e0132879.

45. Caporaso JG, Lauber CL, Walters WA, Berglyons D, Lozupone CA, Turnbaugh PJ, Fierer N, Knight R: Global patterns of 16S rRNA diversity at a depth of millions of sequences per sample. Proc Natl Acad Sci U S A 2011, 108(Supplement_1):4516-4522.

46. Caporaso JG, Lauber CL, Walters WA, Berglyons D, Huntley J, Fierer N, Owens SM, Betley J, Fraser L, Bauer M: Ultra-high-throughput microbial community analysis on the Illumina HiSeq and MiSeq platforms. Isme Journal Multidisciplinary Journal of Microbial Ecology 2012, 6(8):1621-1624.

47. Peiffer JA, Spor A, Koren O, Jin Z, Tringe SG, Dangl JL, Buckler ES, Ley RE: Diversity and heritability of the maize rhizosphere microbiome under field conditions. Proceedings of the National Academy of Sciences of the United States of America 2013, 110(16):6548-6553.

48. Magoč T, Salzberg SL: FLASH: fast length adjustment of short reads to improve genome assemblies. Bioinformatics 2011, 27(21):2957-2963.

49. Bokulich NA, Subramanian S, Faith JJ, Gevers D, Gordon JI, Knight R, Mills DA, Caporaso JG: Quality-filtering vastly improves diversity estimates from Illumina amplicon sequencing. Nature Methods 2013, 10(1):57-59.

50. Caporaso JG, Kuczynski J, Stombaugh J, Bittinger K, Bushman FD, Costello EK, Fierer N, Peã AA AG, Goodrich JK, Gordon JI: QIIME allows analysis of high-throughput community sequencing data. Nature Methods 2010, 7(5):335-336.

51. Edgar RC, Haas BJ, Clemente JC, Quince C, Knight R: UCHIME improves sensitivity and speed of chimera detection. Bioinformatics 2011, 27(16):2194.

52. Haas BJ, Gevers D, Earl AM, Feldgarden M, Ward DV, Giannoukos G, Ciulla D, Tabbaa D, Highlander SK, Sodergren E: Chimeric 16S rRNA sequence formation and detection in Sanger and 454-pyrosequenced PCR amplicons. Genome research 2011, 21(3):494-504.

53. Edgar RC: UPARSE: highly accurate OTU sequences from microbial amplicon reads. Nature Methods 2013, 10(10):996.

54. Christian Q, Elmar P, Pelin Y, Jan G, Timmy S, Pablo Y, J?Rg P, Frank Oliver GC: The SILVA ribosomal RNA gene database project: improved data processing and web-based tools. Nucleic Acids Research 2013, 41(Database issue):590-596. 
55. Wang Q, Garrity GM, Tiedje JM, Cole JR: Naive Bayesian classifier for rapid assignment of rRNA sequences into the new bacterial taxonomy. Applied \& Environmental Microbiology 2007, 73(16):5261.

56. Edgar RC: Local homology recognition and distance measures in linear time using compressed amino acid alphabets. Nucleic Acids Research 2004, 32(1):380-385

57. Li B, Zhang X, Guo F, Wu W, Zhang T: Characterization of tetracycline resistant bacterial community in saline activated sludge using batch stress incubation with high-throughput sequencing analysis. Water Research 2013, 47(13):4207-4216.

58. Guo S: Spatial variations of soil respiration and temperature sensitivity along a steep slope of the semiarid Loess Plateau. Plos One 2018, 13(4):e0195400.

59. M Š, Bárta J, H Š, Baldrian P: Small-scale spatial heterogeneity of ecosystem properties, microbial community composition and microbial activities in a temperate mountain forest soil. Fems Microbiology Ecology 2016, 92(12):fiw185.

60. Lal R: Soil erosion and carbon dynamics. Soil \& Tillage Research 2005, 81(2):137-142

61. Cheng Y, Shao-Shan AN, Yun-Fei MA: Soil Microbial Biomass and Enzymatic Activities in the Loess Hilly Area of Ningxia under Different Slope Positions. Research of Soil \& Water Conservation 2010.

62. Guo C, Jinchuan LI, Yue J, Yang S, Ning LU: Diurnal changes in the photosynthetic characteristics of two high yield and high quality grasses during different stages of growth and their response to changes in light intensity. Acta Ecologica Sinica 2013, 33(6):1751-1761.

63. Fierer N, Schimel JP, Holden PA: Variations in microbial community composition through two soil depth profiles. Soil Biology \& Biochemistry 2003, 35(1):167-176

64. Eilers KG, Debenport S, Anderson S, Fierer N: Digging deeper to find unique microbial communities: The strong effect of depth on the structure of bacterial and archaeal communities in soil. Soil Biology \& Biochemistry 2012, 50(7):58-65.

65. Voříšková J, Brabcová V, Cajthaml T, Baldrian P: Seasonal dynamics of fungal communities in a temperate oak forest soil. New Phytologist 2013, 201(1):269-278.

66. Rousk J, Bååth E, Brookes PC, Lauber CL, Lozupone C, Caporaso JG, Knight R, Fierer N: Soil bacterial and fungal communities across a pH gradient in an arable soil. Isme Journal 2010, 4(10):1340-1351

67. Bartram AK, Xingpeng J, Lynch MDJ, Masella AP, Nicol GW, Jonathan D, Neufeld JD: Exploring links between pH and bacterial community composition in soils from the Craibstone Experimental Farm. Fems Microbiology Ecology 2013, 87(2):403-415.

68. Fierer N: Embracing the unknown: disentangling the complexities of the soil microbiome. Nature Reviews Microbiology 2017, 15(10):579-590.

69. Abed RMM, Kohls K, Palinska KA, Golubic S: Diversity and Role of Cyanobacteria and Aerobic Heterotrophic Microorganisms in Carbon Cycling in Arid Cyanobacterial Mats; 2010.

70. Fierer N, Jackson RB: The diversity and biogeography of soil bacterial communities. Proceedings of the National Academy of Sciences of the United States of America 2006, 103(3):626-631.

71. Harter, nbsp, Robert D: Effect of Soil pH on Adsorption of Lead, Copper, Zinc, and Nickel. Soil Scisocamj 1983, 47(1):47-51.

72. Weil R, Brady N: The Nature and Properties of Soils, Global Edition; 1974.

73. Ibekwe AM, Poss JA, Grattan SR, Grieve CM, Suarez D: Bacterial diversity in cucumber (Cucumis sativus ) mizosphere in response tosalinity, soil pH, and boron. Soil Biology \& Biochemistry 2010, 42(4):567-575.

74. Hong CQ: Effects of root exudates on plant nutrition. Ecological environment 2003, 12:508-511.

75. Zhao XL, Liu XH, Jiang-Zhou HE, Wan CX, Gong MF, Zhang LL: Effects of Cotton Root Exudates on Available Soil Nutrition,Enzyme Activity and Microorganism Quantity. Acta Botanica Boreali-Occidentalia Sinica 2009:1426-1431.

76. Cleveland CC, Townsend AR, Schmidt SK: Phosphorus limitation of microbial processes in moist tropical forests: Evidence from short-term laboratory incubations and field studies. Ecosystems 2002, 5(7):680-691.

77. Cruz AF, Hamel C, Hanson K, Selles F, Zentner RP: Thirty-seven years of soil nitrogen and phosphorus fertility management shapes the structure and function of the soil microbial community in a Brown Chernozem. Plant \& Soil 2009, 315(2):173-184.

78. Eilers KG, Lauber CL, Knight R, Fierer N: Shifts in bacterial community structure associated with inputs of low molecular weight carbon compounds to soil. Soil Biology \& Biochemistry 2010, 42(6):896-903.

79. Henis Y: Soil microorganisms, soil organic matter and soil fertility; 1986.

80. Sparling GP, Pankhurst C, Doube BM, Gupta VVSR: Soil microbial biomass, activity and nutrient cycling as indicators of soil health; 1997.

81. Webster EA, Hopkins DW, Chudek JA, Haslam SF, Simek M, Pîcek T: The relationship between microbial carbon and the resource quality of soil carbon Journal of Environmental Quality 2001, 30(1):147.

82. Castrosowinski S, Herschkovitz Y, Okon Y, Jurkevitch E: Effects of inoculation with plant growth-promoting rhizobacteria on resident ihizosphere microorganisms. Fems Microbiology Letters 2010, 276(1):1-11.

83. Cutler HG, Wells JM: Unusual plantnrowth regulators from microorganisms. Critical Reviews in Plant Sciences, 6(4):323-343.

84. Bourke RM: Influence of nitrogen and potassium fertilizer on growth of sweet potato (Ipomoea batatas) in Papua New Guinea. Field Crops Research 1985, 12(85):363-375.

85. Sarathchandra SU, Lee A, Perrott KW, Rajan S, Oliver E, Gravett IM: Effects of phosphate fertilizer applications on microorganisms in pastoral soil. Australian Journal of Soil Research 1993, 31(3):641-648. 
86. Soto MJ, Domínguezferreras A, Pérezmendoza D, Sanjuán J, Olivares J: Mutualism versus pathogenesis: the give-and-take in plant-bacteria interactions. Cellular Microbiology 2010, 11(3):381-388.

\section{Tables}

TABLE 1 Spearman correlation coefficients between soil physicochemical properties across all samples.

\begin{tabular}{lllllllllll}
\hline & TOC & TN & TP & TK & NN & AN & AP & TS & pH & Altitude \\
\hline TOC & 1.000 & & & & & & & & & \\
\hline TN & $0.792^{* *}$ & 1.000 & & & & & & & & \\
\hline TP & 0.163 & 0.193 & 1.000 & & & & & & & \\
TK & 0.171 & 0.333 & 0.067 & 1.000 & & & & & & \\
\hline NN & 0.356 & 0.277 & -0.149 & -0.079 & 1.000 & & & & & \\
\hline AN & -0.200 & -0.269 & $-0.448^{*}$ & 0.012 & 0.031 & 1.000 & & & & \\
\hline AP & $0.568^{* *}$ & $0.639^{* *}$ & 0.271 & $0.472^{*}$ & 0.069 & -0.230 & 1.000 & & & \\
\hline TS & $0.411^{*}$ & 0.232 & 0.004 & 0.125 & 0.287 & -0.031 & 0.073 & 1.000 & & \\
\hline pH & 0.038 & 0.149 & 0.002 & 0.129 & 0.077 & 0.047 & 0.213 & $-0.390^{*}$ & 1.000 & \\
\hline Altitude & -0.006 & 0.157 & $0.443^{*}$ & 0.221 & $-0.629^{* *}$ & $-0.425^{*}$ & $0.419^{*}$ & -0.093 & -0.245 & 1.000 \\
\hline & & & & & & & & & &
\end{tabular}

Description: TS, total salt content; AP, available phosphorus content; AN, ammonium nitrogen content; NN, nitrate nitrogen content; TP, total phosphorus content; TN, total nitrogen content; TK, total potassium content; TOC, total organic carbon content. r-value represents Spearman correlation coefficient, between -1 and 1 , $r<0$ is negative correlation, $\mathrm{r}>0$ is positive correlation ${ }^{*} p<0.05,{ }^{* *} p<0.01$.

TABLE 2 The spearman correlation analyses between the $\alpha$-diversity index and soil physicochemical properties.

\begin{tabular}{lccccc}
\hline & \multicolumn{2}{c}{ shannon index } & & \multicolumn{2}{c}{ chao1 index } \\
\cline { 2 - 3 } \cline { 6 - 6 } & $\mathbf{r}$ & $\boldsymbol{p}$ & & $\mathbf{r}$ & $\boldsymbol{p}$ \\
\hline Altitude & 0.136 & 0.107 & & 0.175 & 0.383 \\
\hline TOC & 0.234 & 0.240 & & -0.037 & 0.854 \\
TN & 0.185 & 0.356 & & -0.152 & 0.449 \\
\hline TP & 0.459 & $0.016^{*}$ & & 0.114 & 0.571 \\
\hline TK & 0.405 & $0.036^{*}$ & & 0.225 & 0.259 \\
NN & 0.060 & 0.766 & & -0.102 & 0.613 \\
\hline AN & -0.312 & 0.113 & & 0.078 & 0.698 \\
AP & 0.538 & $0.004^{* *}$ & & 0.240 & 0.228 \\
\hline TS & 0.027 & 0.892 & & -0.035 & 0.862 \\
\hline pH & 0.317 & 0.498 & & -0.190 & 0.343 \\
\hline
\end{tabular}

Description: r-value represents spearman correlation coefficient, between -1 and $1, \mathrm{r}<0$ is negative correlation, $\mathrm{r}>0$ is positive correlation $* p<0.05, * * p<0.01$.

TABLE 3 The spearman correlation analysis between relative abundance of dominant bacteria and soil physicochemical properties.

Actinobacteria Firmicutes Proteobacteria Bacteroidetes Planctomycetes Acidobacteria Gemmatimonadetes Chloroflexi Verr

\begin{tabular}{|c|c|c|c|c|c|c|c|c|}
\hline $\mathrm{PH}$ & -0.355 & -0.003 & 0.054 & $0.434^{*}$ & 0.106 & 0.130 & 0.027 & -0.263 \\
\hline TOC & 0.346 & -0.026 & -0.101 & 0.049 & 0.026 & 0.026 & -0.377 & 0.311 \\
\hline $\mathrm{TN}$ & $0.420 *$ & -0.122 & 0.087 & -0.035 & -0.224 & -0.096 & -0.151 & 0.349 \\
\hline $\mathrm{TP}$ & -0.026 & -0.279 & 0.314 & 0.278 & 0.012 & 0.120 & 0.178 & -0.065 \\
\hline TK & 0.246 & -0.114 & 0.026 & 0.071 & -0.006 & 0.300 & -0.007 & 0.337 \\
\hline NN & 0.018 & -0.083 & -0.004 & 0.351 & -0.040 & 0.028 & $-0.564^{* *}$ & 0.007 \\
\hline AN & 0.226 & -0.024 & -0.162 & -0.137 & 0.174 & 0.049 & 0.067 & 0.196 \\
\hline $\mathrm{AP}$ & $0.445^{*}$ & -0.206 & 0.187 & 0.201 & -0.156 & -0.002 & -0.012 & $0.411^{*}$ \\
\hline TS & $0.443^{*}$ & -0.169 & -0.238 & -0.206 & -0.090 & 0.027 & $-0.394^{*}$ & $0.394 *$ \\
\hline Altitude & 0.169 & -0.093 & 0.175 & -0.186 & -0.274 & -0.076 & $0.478^{*}$ & 0.169 \\
\hline
\end{tabular}

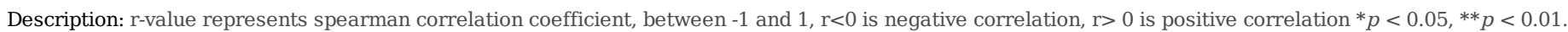




\section{Figures}

\section{Figure 1}

UPGMA clustering using weighted Unifrac distances showed abundance information for the top ten bacterial phyla of each group. Description: E, R and S represent the rhizosphere region of the top, middle and bottom of the slope respectively. NE, NR and NS represent the non-rhizosphere region of the top, middle and bottom of the slope respectively. The numbers indicate root depths, 1,2 and 3 representing depths of $0-10 \mathrm{~cm}, 10-25 \mathrm{~cm}$ and $25-40 \mathrm{~cm}$, respectively.

as

\section{Figure 2}

Results of intergroup LDA effect size (LEfSe) analysis revealed the specific bacteria phylum and genus distributed in the rhizosphere and non-rhizosphere regions under different slope positions and soil depths. Description: Each small circle at a different classification level represents a classification at this level and the diameter of the small circle is proportional to the relative abundance. Species with no significant differences are uniformly colored in yellow, the different species Biomarker follows the group for coloring.

as

\section{Figure 3}

Ordination diagram (samples-environment biplot) of db-RDA depicting environmental drivers of rhizosphere bacterial community composition of Ferula sinkiangensis.

屏

\section{Figure 4}

Spearman correlation between $\mathrm{pH}(\mathrm{A})$, altitude (B) and dominant bacteria. Description: " + " indicates positive correlation; “-” indicates negative correlation * $<$ $0.05,{ }^{*} \mathrm{p}<0.01$.

\section{Supplementary Files}

This is a list of supplementary files associated with this preprint. Click to download.

- Supplementarytableandfigure.docx 